\title{
CONSIDERACIONS SOBRE ELS CONEIXEMENTS QUE HAURIEN DE POSSEIR ELS MESTRES CATALANS PER A UNA BONA PRÀCTICA DOCENT DE LES CIÈNCIES SOCIALS
}

\author{
Maria dels Dolors Olivé Vallès. Àrea de Didàctica de les Ciències Socials. Universitat Ramon Llull
}

Les inquietuds pedagògiques que em dugueren a cursar estudis de Magisteri i a exercir en una escola primària, sense trencar els lligams amb una Escola de Mestres, em van impulsar a qüestionar-me com des de la ciència, i concretament des de la Geografia, es pot contribuir a la formació de l'infant i de l'adolescent, i formar ciutadans capaços de participar activament en la millora pròpia i del seu entorn.

Les experiències viscudes, com ara les sortides matinals, les excursions, els viatges, la convivència amb gent d'altres cultures fora de l'àmbit territorial, m'ajudaven a descobrir el món, però necessitava un aprofundiment, un estudi rigorós que em permetés respondre a qüestions que se'm plantejaven. Aquest desig va ser l'impuls que em dugué a prendre finalment l'opció d'estudiar la llicenciatura de Geografia, ciència que, com la Història, m'atreia des de la infantesa. No obstant això, mai no he pogut oblidar que l'ensenyament rebut a l'escola primària havia estat eminentment memorístic, poc significatiu, fruit d'una metodologia a les aules d'alguns centres escolars en una època concreta. Això feia que l'interès per la interpretació dels fenòmens físics i humans del nostre món pogués derivar, en alguns casos, en un sentiment de refús envers les Ciències Socials (CCSS), tant a l'escola primària com a la secundària, fet que he pogut constatar en l'exercici docent.

Després de l'experiència de catorze anys d'ensenyament de la Geografia i de la Didàctica de les Ciències Socials a l'Escola de Mestres Blanquerna, i en un moment de transformació de tot el sistema educatiu espanyol amb la implantació de la Llei Orgànica d'Ordenació General del Sistema Educatiu (LOGSE) de 1990, en què s'exigia un nou replantejament en la formació del professorat de l'ensenyament primari, vaig dur a terme una investigació sobre Els problemes de la Didàctica de les Ciències Socials a les Escoles de Mestres de Catalunya. La seva finalitat primordial era conèixer i valorar la situació del seu ensenyament en un moment de canvi del sistema educatiu i perfilar unes línies de millora en el futur immediat. Volia saber com s'impartien les didàctiques específiques en aquestes Escoles Universitàries de Formació del Professorat d’EGB, la situació dels estudiants que es preparaven per ser mestres, els seus coneixements científics i quina formació professional adquiririen durant els tres anys de la carrera.

\section{Àmbit de la recerca}

Vaig iniciar la recerca l'any 1990 i la vaig acabar l'agost de 1994 (comprèn, doncs, el període inicial de la Reforma Educativa i les situacions de canvi que vivien les Escoles de Formació del Professorat d'EGB). Fa, doncs, un decenni. La reflexió que faig ara és per veure com estàvem i si en aquest període hi ha hagut canvis. Avanço ja que sí, i molts, però deixeu-m'ho argumentar.

Vaig escollir una mostra que fos significativa: les Escoles de Mestres existents en aquell moment, que estaven sota la jurisdicció de la Conselleria d'Ensenyament de la Generalitat de Catalunya, i per tant sotmeses a unes mateixes orientacions i normatives. Tot i així, no es pot dir que hi hagués homogeneïtat, car cada escola tenia un dinamisme propi, el qual quedava reflectit en una metodologia i organització de les matèries didàctiques diferents (diverses maneres de fer o de concebre la Didàctica de les CCSS). En el curs 1990-91 existien a Catalunya set Escoles de Formació del Professorat d'EGB, també anomenades, segons la legislació o el pensament pedagògic, Escoles Normals, Escoles de Magisteri o Escoles de Mestres. En la taula 1 hom pot veure la relació d'aquestes Escoles de Mestres ordenades per ordre drecreixent del nombre d'alumnes corresponent a aquell curs (s'hi han afegit els professors entrevistats de cada centre).

Els professors entrevistats van ser 32, dels quals 29 impartien la Didàctica de les CCSS o la didàctica específica d'alguna de les matèries del Departament de CCSS i els tres restants havien estat baixa de les escoles 


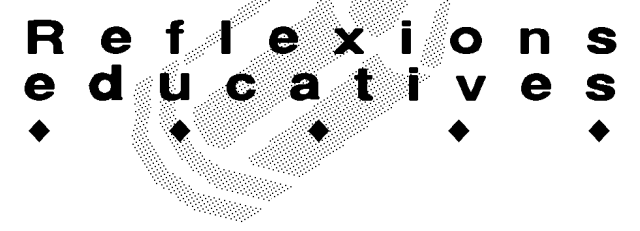

l'any anterior per jubilació o canvi de lloc de treball.

\section{Definició de la recerca}

Tres van ser els objectius del treball:

1. Conèixer l'estat de l'ensenyament de la Didàctica de les CCSS i del professorat.

Mostrar els continguts de Didàctica de les CCSS que s'impartien al moment d'iniciar-se la reforma educativa i abans d'implantar-se els nous plans d'estudis.

Comprovar si els programes eren actualitzats d'acord amb la realitat sociocultural, amb els nous corrents científics i amb la pràctica educativa.

Constatar la preparació professional dels professors per la formació rebuda, per l'experiència docent i per les activitats de perfeccionament que duen a terme.

2. Veure si els nous plans d'estudis (MEC, 1991) millorarien la formació dels mestres respecte als plans vigents el curs 1990-91, en l'àrea de Didàctica de les CCSS.

3. Mostrar els aspectes de la reforma educativa que causen millores en un futur immediat en l'àrea de les CCSS.

Proposàvem destacar els punts de canvi que milloressin la situació anterior i els que es creu que no ajudarien a augmentar la qualitat dels futurs mestres.

\section{La metodologia}

Com a mètode de treball vaig utilitzar l'entrevista normalitzada. Vaig recórrer a aquest procediment i no a la realització d'enquestes perquè volia recollir al màxim les opinions dels professors, les seves justificacions, els seus suggeriments i les propostes que podien exposar lliurement. L'entrevista utilitzada va ser dirigida (PARDINAS, 1989). Es va seguir un guió que prèviament s'havia enviat als interessats a fi que el llegissin i pensessin en

$\begin{array}{lccc}\begin{array}{l}\text { Escola de } \\ \text { Mestres }\end{array} & \begin{array}{c}\text { alumnes } \\ \text { del centre }\end{array} & \begin{array}{c}\text { \% d'alumnes } \\ \text { sobre el total }\end{array} & \begin{array}{c}\text { professors } \\ \text { entrevistats }\end{array} \\ \text { Barcelona } & 3009 & 41,5 & 14 \\ \text { "Sant Cugat" (UAB) } & 1684 & 23,2 & 7 \\ \text { "Blanquerna" } & 898 & 12,4 & 4 \\ \text { Girona } & 553 & 7,6 & 1 \\ \text { Lleida } & 483 & 6,7 & 1 \\ \text { Tarragona } & 446 & 6,2 & 2 \\ \text { "Balmes" (Vic) } & 173 & 2,4 & 3 \\ \text { Totals } & 7264 & 100,0 & 32\end{array}$

Taula 1. Relació numèrica d'alumnes a les Escoles de Mestres (curs 1990-91) i de professors entrevistats. les qüestions que se'ls plantejaria a l'hora de fer l'entrevista. El guió constava d'onze fulls, amb 63 ítems. S'hi podien distingir: les dades personals, la preparació professional, l'experiència docent a tots els nivells educatius, l'estatus laboral a l'Escola de Mestres, la Didàctica de les CCSS a les Escoles de Mestres i la Didàctica de les CCSS en els nous plans d'estudis.

Hi havia preguntes tancades en les dades personals, estatus laboral, part de les corresponents a la preparació professional, docència i Didàctica de les CCSS. La resta de preguntes eren obertes o múltiples, on l'entrevistat podia respondre com volgués, però dins d'un marc estructurat que venia donat en el guió.

Per poder contrastar el parer del professorat sobre el concepte de Didàctica de les CCSS amb la seva aplicació a l'aula vaig demanar els programes de les assignatures als mateixos entrevistats. Vaig utilitzar altres materials per poder contrastar, en alguns aspectes, la valoració dels resultats obtinguts amb les opinions dels alumnes de tercer curs de les últimes promocions del Pla 1971 amb la informació facilitada pel Dr. Àngel Forner, catedràtic de l'Escola de Mestres de la Universitat de Barcelona, del seu treball d'investigació: Avaluació de les perspectives professionals i del pensament pedagògic dels futurs mestres (FORNER, 1993).

\section{Resultats objectius de l'entrevista}

L'anàlisi del contingut va ser feta quantitativament $i$ qualitativa, d'acord amb Eduardo López Aranguren (1986), que considera tots dos mètodes complementaris l'un de l'altre. En la transcripció dels resultats vaig seguir el sistema de categories del mateix autor, d'acord amb el contingut que es pretenia analitzar. Les aportacions foren molt interessants i valuoses, i ara anomeno alguns dels aspectes tractats en l'entrevista i alguns dels resultats:

- Les dades personals: el sexe (66\% del sexe femení i el $34 \%$ del sexe masculí). Majoritàriament, els professors tenien una edat compresa entre 36 i 50 anys (59\%).

- La preparació professional: els professors que van estudiar Magisteri eren 17 (53\%), dels quals 16 van exercir a Preescolar i/o EGB. Les llicenciatures cursades eren: Filosofia i Lletres, Geografia, Geografia i Història, Història, Art. Si més de la meitat dels professors eren mestres, quatre van emplenar el seu currículum amb dues llicenciatures. En el moment de l'entrevista el professorat de les Escoles de Mestres impartia el primer cicle universitari. Un $72 \%$ del professorat havia obtingut el grau de doctor 0 estava en vies d'aconseguir-lo; d'aquests n'hi havia 14 la tesi dels quals versava sobre didàctica. La preparació psicopedagògica i de didàctica dins dels estudis cursats corresponia al $53 \%$ dels entrevistats. 


\section{$R$ e f \\ e d u c a t i v e s}

- Tenien experiència docent als nivells educatius: Preescolar 16\%, EGB 81\%, Magisteri 100\%, FP 19\%, BUP 56\%, Facultats 28\%, activitat de Formació Permanent $66 \%$.

- La Didàctica de les Ciències Socials a les Escoles de Mestres:

* Els professors consideraven que en la relació dels grups d'alumnes per professor l'òptim seria 20 alumnes per a les classes pràctiques i 40 per a les teòriques.

* Les dificultats en la docència eren degudes: als alumnes (nombre, preparació, motivació, dedicació), a l'escola (espais, instal-lacions, materials, organització i planificació, temporització i horaris), al pla d'estudis (nombre massa elevat d'assignatures, distribució de les pràctiques d'ensenyament).

* La dedicació setmanal del professorat als estudiants era a través d'entrevistes, seminaris, sortides, pràctiques.

* El $78 \%$ de les entrevistes manifestaven que en les reunions de departament treballaven la didàctica i coordinació de les assignatures.

* Els contextos i problemes de la Didàctica de les CCSS feien referència a la formació del mestre, a la preparació professional i personal. Es podia observar que el que quedava més assolit eren els continguts, i el que menys, la formació personal. A la pregunta de si per ensenyar la didàctica calia tenir assolits els continguts de la matèria, el $75 \%$ dels entrevistats opinava que s'havia de fer una selecció per ingressar en una Escola de Mestres (es podria exigir la motivació per a la docència $\mathrm{i}$ unes aptituds imprescindibles per a ser un bon mestre).

* Una dificultat latent a les Escoles de Mestres era la relació entre teoria i pràctica. No tots els professors van reflexionar o valorar de la mateixa manera sobre la metodologia pel fet de no expressar-la en el programa o de no contestar les preguntes. Els professors van exposar diverses maneres de treballar l'avaluació (els exàmens i els treballs eren els principals mitjans de l'avaluació per al $41 \%$, mentre que el $25 \%$ avaluava, a més, altres aspectes, com les pràctiques realitzades, els valors i les actituds, la manera de treballar, les sortides, les exposicions dels treballs, etc.

- La Didàctica de les Ciències Socials en els nous plans d'estudis: Aquesta última part de l'entrevista recollia la preo-

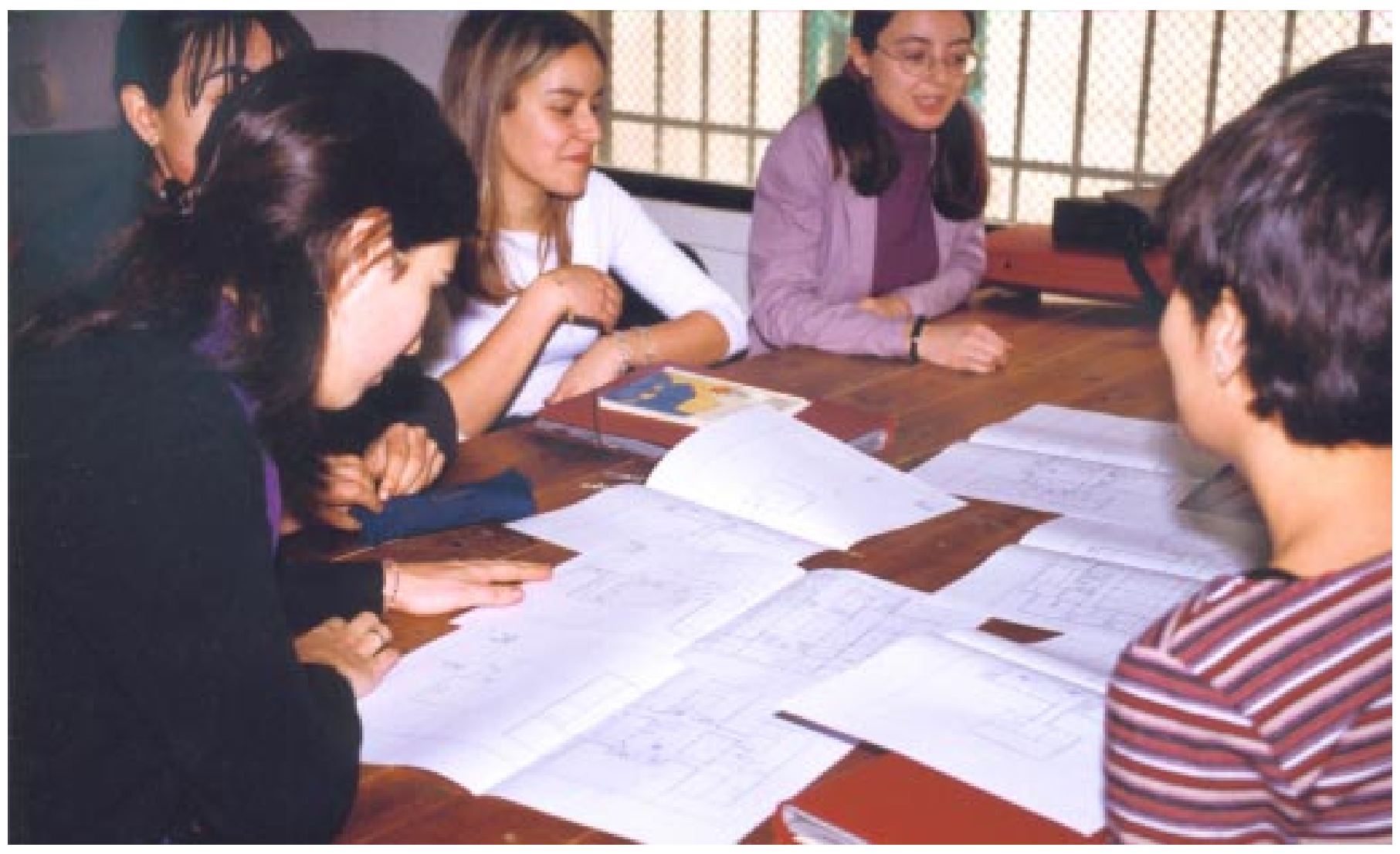




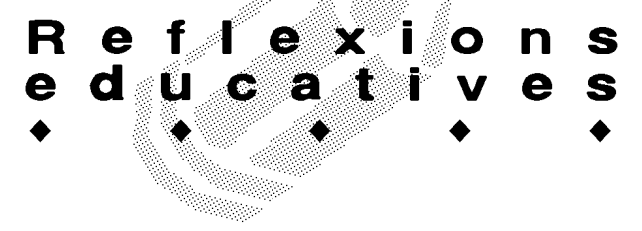

cupació o sensibilitat del professorat davant la Reforma d'Ensenyament. Es demanaven les matèries acadèmiques que s'haurien d'impartir per preparar els mestres per fer classes de CCSS en l'ensenyament primari i també la importància de la Didàctica de les CCSS en la formació del mestre generalista: aspectes fonamentals i els objectius, continguts i activitats que s'havien de tractar. Amb els resultats obtinguts s'arribava a pensar que:

* Els professors donaven més prioritat als continguts de CCSS que a la didàctica.

* Es donava importància a les matèries instrumentals per poder accedir més fàcilment als continguts de CCSS.

* No tots els professors estaven prou al corrent de les innovacions que comportava la reforma d'ensenyament.

* L'ensenyament de l'Educació en el Medi s'havia d'incloure en els nous plans d'estudis.

\section{Línies fonamentals conclusives}

Amb els resultats obtinguts de les valoracions de les entrevistes, l'avaluació del conjunt del contrast entre la visió del professorat i la dels alumnes, i la legislació sorgida arran de la reforma educativa que afectava els punts tractats en el treball per veure les convergències $i$ divergències que se'n desprenien, vaig arribar a les conclusions, la síntesi de les quals és la següent:

Les Escoles de Mestres o Facultats com a centres superiors que formen professionals de l'ensenyament primari:

- Les Escoles de Mestres no poden seleccionar els seus alumnes d'acord amb les seves aptituds per ser professionals de l'ensenyament, sinó solament per haver superat uns continguts conceptuals.

- La transformació de les Escoles de Mestres en Facultats d'Educació permet augmentar l'estatus docent dels professors i l'exigència en el camp de la recerca educativa. Tanmateix, les escoles asseguraven una visió global de la professió que pot quedar diluïda en la suma de crèdits automatitzats. El problema és més greu si considerem que el professor de primària és un mestre generalista.

- Es proposa l'avaluació de la tasca educativa dels professors dels futurs mestres per part de tres instàncies: del centre, de les escoles de primària on actuïn i dels mateixos alumnes.

- Crec que és important promoure les estades o anys sabàtics en centres educatius importants, tant nacionals com internacionals, prèvia presentació d'un projecte i, en acabar, d'una memòria del treball realitzat.

- Constato que gran part de les dificultats per dur a terme un ensenyament de la didàctica de les CCSS és ocasionada per una deficiència en l'organització i funcionament dels centres, la qual cosa repercuteix en l'horari lectiu, en la utilització dels espais i recursos didàctics, i en l'horari disponible dels professors per a reunions i de dedicació als alumnes.

- Aquestes dificultats poden continuar amb la pluralitat d'assignatures del pla nou (optatives i de lliure configuració) que obstaculitzen la disponibilitat d'espais i temps per dur a terme activitats acadèmiques que no siguin estrictament les hores lectives.

- Considero la creació dels Departaments de Didàctica de les CCSS com un dels encerts que preveu la legislació actual, perquè permetrà canalitzar una sèrie d'iniciatives i propostes fetes pels professors entrevistats.

El professorat com a formador de mestres:

- La professionalització continua essent poc valorada, en no exigir al professorat, com a condició per poder formar els mestres, el títol de Magisteri, haver exercit la seva professió un cert període de temps o tenir la llicenciatura en Ciències de l'Educació amb experiència per haver treballat a l'escola primària. La llicenciatura, segons l'àrea on exerceixi el professor/a, caldria que anés acompanyada de la formació didàctica específica.

- La LRU no ha donat cap requisit específic per accedir a les places de formació del professorat. Continua existint, per tant, la possibilitat que els mestres puguin ésser formats per professors que desconeguin l'escola primària en faltar-los l'experiència en aquest nivell.

- S'ha evidenciat, en algunes escoles, que els professors de Psicopedagogia organitzen i controlen les pràctiques, i que els professors de didàctiques específiques no s'hi troben prou implicats. Això suposa un replantejament nou del pràcticum i la potenciació del professor-tutor.

- Els formadors de futurs formadors no s'han vist, generalment, obligats a reciclar-se en la didàctica. L'Escola de Mestres hauria de tenir, en la seva organització, espais de temps per a reunions de didàctica, seminaris que ajudessin a posar en comú l'experiència i el saber, i també l'organització de trobades de professors per intercanviar les recerques més noves.

- A les Escoles de Mestres que no tenen constituït el Departament de Didàctica de les CCSS els 


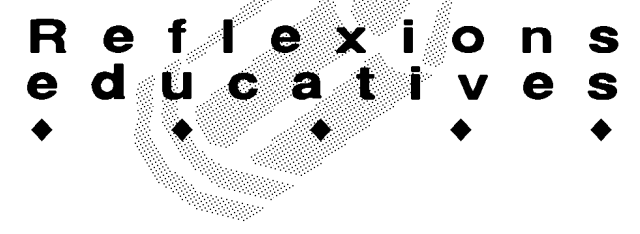

falta organitzar sistemàticament seminaris específics i treballs conjunts dels professors de didàctiques específiques amb els professors de psicopedagogia i mestres en exercici.

- Probablement no s'ha potenciat prou la investigació educativa i no s'ha exigit periòdicament la realització de projectes nous, com ara treballs d'investigació entre professors d'Escoles Normals i mestres, i si escau, amb estudiants de Magisteri. No obstant això, aquesta situació està millorant amb la nova legislació, que regula la formació permanent del professorat.

- Els professors tenen poca pràctica educativa en una aula de l'escola primària, car els falta poder aplicar la teoria a la pràctica $\mathrm{i}$ avaluar-ne els resultats. Aquesta pràctica hauria de ser habitual dels professors (tal com succeeix en països com la Gran Bretanya, els EUA i Suècia, on el professor exerceix la seva professió, cada cinc anys, en un centre de primària).

Els plans d'estudis com a configuradors d'un perfil de mestre:

- El marc proposat pel "Consejo de Universidades" limita les universitats, i en concret les Escoles de Mestres (actualment algunes convertides en Facultats de Ciències de l'Educació), a l'hora de dissenyar uns plans d'estudis que assegurin la formació del mestre generalista en diverses àrees, $i$ en d'altres el d'especialista, sense detriment en cap dels dos àmbits educatius.

- En el pla nou es fa difícil valorar la implicació de l'àrea de CCSS per no poder determinar la seva incidència en les matèries optatives i de lliure configuració. Pertany a l'arbitri de cada universitat la implantació a cada any acadèmic d'aquestes assignatures, segons la disponibilitat de professorat, recursos, etc.

- Els nous plans d'estudis, en pretendre formar mestres generalistes $i$ especialistes amb la mateixa durada dels estudis que el pla 1971, augmentant el nombre d'assignatures i reduint els crèdits, duen a una multiplicitat d'assignatures sense un aprofundiment. Aquests plans s'oposen al parer dels professors entrevistats de reduir el nombre d'assignatures.

- No s'ha aconseguit que els estudis de Magisteri esdevinguin una llicenciatura. Amb un any més de la carrera s'hauria pogut reforçar més la professionalització amb pràctiques a les escoles de primària i treballs de seminaris.

- Els nous plans, amb la distribució de crèdits en teòrics i pràctics, semblen un primer pas per mi- llorar la metodologia de les assignatures.

- No es pot generalitzar, en aquests moments, la bona preparació dels mestres en la Didàctica de les CCSS, per diversos motius: depèn de l'especialitat cursada. Els alumnes d'Educació Primària i d'Educació Infantil surten més ben preparats que els altres especialistes, perquè tenen més crèdits de matèries troncals i obligatòries, imposades per algunes universitats. Les especialitats d'Educació Física, Educació Musical i Llengua Estrangera disposen de pocs crèdits de didàctica en el Coneixement del Medi Natural, Social i Cultural (alguns centres tenen el mínim, 40 hores), i el seu títol els habilita per fer classes d'aquesta àrea a tot l'ensenyament primari.

- Els alumnes poden fer itineraris diversos quedantse en els mínims o escollir matèries de didàctiques de l'àrea de CCSS com a matèries optatives o de lliure configuració. La impartició de matèries optatives homologades de l'àrea de CCSS dependrà cada any de la proposta que faci la universitat segons les seves disponibilitats.

Els alumnes com a futurs professionals que han de respondre a les necessitats $i$ exigències de la societat actual i futura:

- L'alumnat té poc domini dels continguts de les disciplines integrants de les CCSS. No es pot pensar com ensenyar sense que el mestre tingui una visió general de les disciplines que s'han d'impartir.

- Els "complements de formació" que figuren en els plans nous poden assegurar o augmentar el nivell dels continguts dels alumnes, remeiant les dificultats manifestades pels professors sobre el seu baix nivell, que dificulta l'ensenyament de les didàctiques específiques.

- Les universitats i la legislació actual semblen no haver-se plantejat la reducció del nombre d'alumnes per professor per millorar la qualitat de l'ensenyament. Si no es posa una limitació, difícilment podran fer-se les classes pràctiques, els seminaris i mantenir una relació professor-alumne que pugui repercutir positivament en la formació personal del mestre.

La formació professional com a objectiu principal de les Escoles de Mestres:

- En general, els estudiants realitzen poques pràctiques educatives i depèn de cada Escola de Mestres la manera de dur-les a terme.

- Es proposen actuacions com:

Els professors de didàctiques específiques haurien de fer el seguiment dels estudiants en la seva 


\section{$R$ ef e x i o n s
ed ucat}

actuació al centre de primària, connectant amb els mestres-tutors per fer-los un guiatge conjunt, suggerir als estudiants accions educatives i proposar-los activitats didàctiques $i$ els mitjans adequats perquè aprenguin a ensenyar d'acord amb les característiques de l'escola i els seus alumnes.

El seguiment ha de poder arribar a una valoració de l'experiència, una crítica de les actuacions i una confrontació dels resultats de la pràctica amb la teoria. Aquesta actuació seria enriquidora per a tots els implicats: no es donaria la separació entre una teoria adquirida a les Escoles de Mestres i una pràctica a l'escola primària, i seria avançar en el millorament del sistema educatiu. Per una banda, els professors de les Escoles de Mestres no estarien desconnectats de la realitat escolar, i per l'altra, els futurs mestres haurien adquirit la formació adequada i crítica sobre l'acció educativa per poder actuar a l'aula i no reproduir antics esquemes i mètodes d'ensenyament rebuts en la seva infantesa i que han quedat obsolets.

Han passat quinze anys després d'haver iniciat l'esmentat estudi i ens trobem en una altra realitat social, econòmica, política i tecnològica, que exigeix nous plantejaments en la formació dels mestres que han d'educar els infants en una societat canviant i cada vegada més globalitzada. Des del punt de vista formatiu també ens trobem en una nova situació: les Escoles de Mestres estudiades formen part de les Facultats de
Ciències de l'Educació amb els departaments ja consolidats; a més de les set universitats que imparteixen els estudis de Magisteri, hi ha la Universitat Internacional de Catalunya (UIC) de nova creació. Són, per tant, vuit universitats a Catalunya que ofereixen aquesta titulació segons les dades facilitades pel Departament d'Universitats, Recerca i Societat de la Informació (DURSI, 2005).

La "Asociación Universitaria de Profesorado de Didáctica de las Ciencias Sociales" (1990) ha potenciat, des dels seus inicis el 1989 com a àrea de coneixement, la Didàctica de les CCSS. Organitza una reunió científica anual -a la primera, realitzada a Còrdova, ja es va plantejar el currículum de Didàctica de les CCSS per a la formació de professors d'educació infantil, primària i secundària- donant un impuls a la investigació, assessorament, difusió, intercanvi de la Didàctica de les CCSS i vetlla per l'actualització i millorament de la didàctica. És un bon marc on el professorat de Didàctica de les CCSS pot trobar-se, dialogar, intercanviar les recerques gestionades en els departaments universitaris i actualitzar-se.

Amb la creació de l'Agència per a la Qualitat del Sistema Universitari a Catalunya (AQU), el setembre de 1996 s'ha iniciat un procés d'avaluació de la qualitat de l'ensenyament universitari: titulacions i programes, professorat, recerca, projecció europea i internacional que sens dubte resol alguns dels problemes detectats en el treball (DURSI, 2005).

Arran de la declaració de Bolonya el 1999, ens

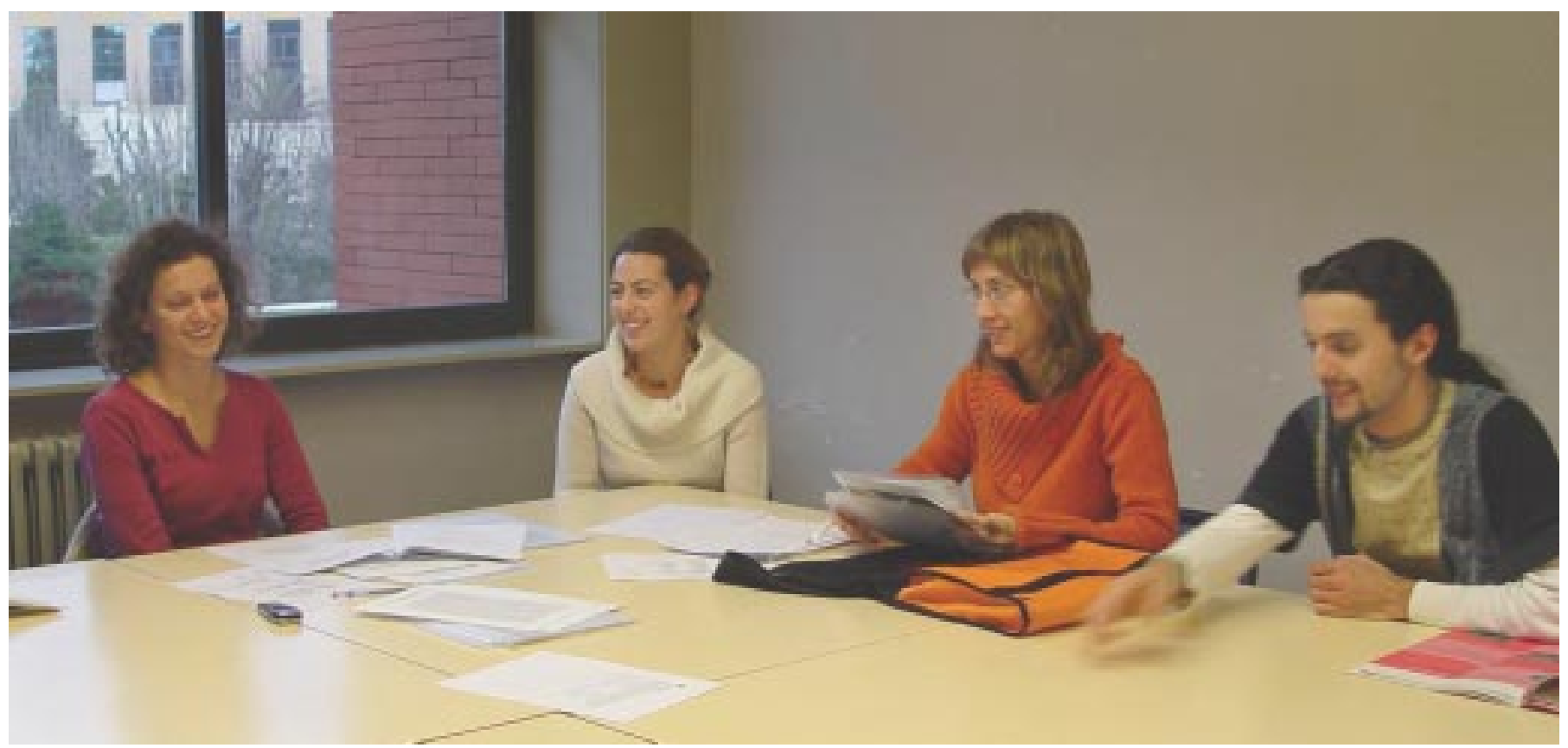




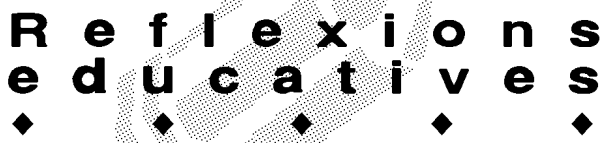

trobem en un nou àmbit europeu d'educació superior per donar resposta a les necessitats de la societat del coneixement. Es posa com a objectius la formació de l'individu en competències, en les quals inclou, a més dels coneixements, les activitats i les actituds per al lloc de treball; en el cas que ens ocupa és formar mestres competents (MORA, J-G. 2004). La Llei d'Universitats de Catalunya (LUC) es planteja en l'article 5 l'educació en valors: responsabilitat, convivència, solidaritat, participació i ciutadania plena, com a part integral del procés d'aprenentatge i formació dels estudiants (DURSI, 2005).

La integració a Europa en un espai d'educació superior, on es preveu la mobilitat d'estudiants amb la consegüent equiparació dels seus currículums a fi de poder accedir a un lloc de treball dins l'àmbit europeu, exigeix un plantejament del currículum de Magisteri amb la possibilitat que la formació del mestre esdevingui un estudi de grau de quatre anys; es vol un mestre generalista amb dues titulacions: educació infantil i educació primària. La "Agencia Nacional de Evaluación de la Calidad y Acreditación" (ANECA, 2004) va encarregar a les Facultats d'Educació i Escoles de Mestres un projecte en el qual es proposa una forta formació en competències bàsiques (saber fer, saber estar i saber ser), implantació dels crèdits europeus, en què l'alumne passa d'un model basat en l'ensenyament a un altre basat en l'aprenentatge i amb una formació molt més interdisciplinària. També cal que la proposta reculli el rol del mestre com a futur formador de mestres, sigui en el pla d'estudis de Magisteri o en la formació continuada, tal com manifesta Riera (2003), millorar la relació entre la teoria i la pràctica, la qual cosa implica una major coordinació entre els tutors de les facultats i els mestres de primària per donar més coherència entre els coneixements teòrics $i$ les experiències pràctiques. Coincideixo amb el que va exposar Benejam (2004) en la lliçó magistral pronunciada en el III Simpòsium sobre l'ensenyament de les Ciències Socials, respecte a la necessitat que els tutors de la universitat tinguin un coneixement pràctic de l'escola, siguin reclutats entre les persones de reconegut prestigi docent i puguin renovar aquesta pràctica periòdicament. Tanmateix, els mestres tutors han de poder rebre una formació teòrica i pràctica per formar els futurs docents (actualment s'han realitzat en algunes facultats universitàries actuacions en aquest sentit).

Ens trobem davant d'un nou context que serà un gran pas endavant en el camí transcorregut fins ara, i que invita a iniciar recerques per verificar fins a quin punt els coneixements que haurien de posseir els mestres catalans per a una bona pràctica docent de les Ciències Socials són una realitat.

\section{Referències bibliogràfiques}

AGENCIA NACIONAL DE EVALUACIÓN DE LA CALIDAD Y ACREDITACIÓN. Competencias específicas de formación disciplinar y profesional. (2004) 84-181. [en línia]. Accessible ahttp://www.aneca.es/modal eval/docs/libroblan co jun05 magisterio1 (consulta 31-8-05).

ASOCIACIÓN UNIVERSITARIA DE PROFESORES DE DIDÁCTICA DE LAS CIENCIAS SOCIALES. «Boletín de didáctica de las ciencias sociales", 1 (1990). Escoles de Mestres Sant Cugat i E.U. de Magisterio de Córdoba. [en línia]. Accessible a http://www.didactica-ciencias-sociales.org (consulta 258-05).

BENEJAM, P. De la teoria... a l'aula. Reflexions sobre fer de mestre. Departament de Didàctica de la Llengua, de la Literatura i de les Ciències Socials. Facultat de Ciències de I'Educació. Universitat Autònoma de Barcelona. Bellaterra. 2004.

DEPARTAMENT D'UNIVERSITATS, RECERCA I SOCIETAT DE LA INFORMACIÓ (2005). Generalitat de Catalunya. 2005. [en línia]. Accessible a http://www10.gencat.net/dursi/ ca/un/luc preliminar.htm (consulta 25-8-05).

FORNER, A. Avaluació de les perspectives professionals $i$ del pensament pedagògic dels futurs mestres. Departament de Mètodes d'Investigació i Diagnòstic en Educació. Escola Universitària de Formació del Professorat. Universitat de Barcelona. Barcelona. 1993. (treball inèdit).

LÓPEZ ARANGUREN, E. El Análisis de Contenido. El análisis de la realidad social: Métodos y técnicas de investigación. Alianza Editorial. Madrid. 1986. pàg. 383-414.

MINISTERIO DE EDUCACIÓN Y CIENCIA. Ley Orgánica 1/1990 de Ordenación General del Sistema Educativo, de 3 de octubre. B.O.E. núm. 238, de 4 de noviembre de 1990.

MINISTERIO DE EDUCACIÓN Y CIENCIA. Decreto 1440/ 1991, de 30 de agosto. B.O.E. núm. 244, de 11 de noviembre de 1991.

MINISTERIO DE EDUCACIÓN Y CIENCIA. Ley 11/1983 de Reforma Universitaria, de 25 de agosto. B.O.E. núm. 209, de 1 de septiembre de 1983.

MORA, J.-G. Els canvis del model universitari com a conseqüència de les noves demandes de la societat del coneixement. "Coneixement i Societat», 6 (2004) 74-91.

OLIVÉ, M.D. Problemes actuals de la Didàctica de les Ciències Socials a les Escoles de Mestres de Catalunya davant la Reforma Educativa. Departament de Geografia Física i Anàlisi Geogràfica Regional. Facultat de Geografia i Història. Universitat de Barcelona. Barcelona. 1994. (tesi doctoral inèdita).

PARDINAS, F. Metodología y técnicas de investigación en Ciencias Sociales. Edit. Siglo XXI, 31a. ed. México. 1989.

RIERA, F. Què saben i què han après les estudiants de mestra de primària per ensenyar ciències socials? Un estudi de cas sobre la formació inicial en Didàctica de les Ciències Socials a Blanquerna - URL. Departament de Didàctica de la Llengua, de la Literatura i de les Ciències Socials. Facultat de Ciències de l'Educació. Universitat Autònoma de Barcelona. Bellaterra. 2003. (tesi doctoral inèdita). 